\title{
Screening of Maize Germplasm for Resistance against Fusarium Stalk Rot caused by Fusarium verticillioides
}

\author{
Ayesha Tabassum ${ }^{1}$, V. B. Sanath Kumar ${ }^{2 *}$ and N. Kiran Kumar ${ }^{2}$ \\ ${ }^{1}$ Department of Agriculture, ${ }^{2}$ Department of Plant Pathology, College of Agriculture \\ (UAS-Bangalore), V.C. Farm Mandya - 571405, Karnataka, India \\ *Corresponding author
}

\begin{tabular}{l} 
K e y w o r d s \\
Fusarium stalk rot, \\
Inbred line, \\
Resistance, \\
Tolerant, \\
Susceptible \\
\hline Article Info \\
$\begin{array}{l}\text { Accepted: } \\
\text { 26 April } 2020 \\
\text { Available Online: } \\
10 \text { May } 2020\end{array}$ \\
\hline
\end{tabular}

Maize is one of the most important cereal crops with a wide adaptability under varied environmental conditions. Universally, maize is recognized as "queen of cereals" because of its immense genetic yield potential compared to other cereals but due to Fusarium stalk rot, yield loss goes up to 42 per cent. To identify a resistant source in maize for Fusarium stalk rot fifty maize inbred lines were screened. Fourteen inbred lines viz., VL1010764, VL05616, VL0511321, VL107730, VL1018807, VL1043, VL108808, VL1244, VL124, SNL153296, VL0512423, VL1047, VL1050 and VL1053 expressed a resistant reaction with a mean disease score of 2.49 and none were found to be highly resistant.

\section{Introduction}

Maize (Zea mays L.) is an important cereal crop of the world and the main centre of origin is considered to be the Central America and Mexico. Universally, maize is recognized as "queen of cereals" because of its immense genetic yield potential compared to other cereals (Anon., 2012). Maize is consumed as a staple food in many parts of the world because of its wide environmental adaptability. It is a third foremost crop of the world after rice and wheat and is grown worldwide over an area of 177 million hectares with a production of 960 million tonnes and productivity of $5,500 \mathrm{~kg} \mathrm{ha}^{-1}$ (Sandhu et al., 2007).

Maize is third most important cereal after rice and wheat in India which is grown over an area of 8.69 million hectares with a production of 21.80 million tonnes and 
productivity of $2,509 \mathrm{~kg} \mathrm{ha}^{-1}$. In Karnataka, it is cultivated over an area of 1.18 million hectares with a production of 3.27 million tonnes and productivity of $2,773 \mathrm{~kg} \mathrm{ha}^{-1}$ (Anon., 2017).

The important maize growing districts of the Karnataka state are Davanagere, Haveri, Belgaum, Bagalkot, Shivamogga, Bengaluru rural, Bellary, Bijapur, Chamarajanagar, Chitradurga, Gulbarga, Dharwad, Gadag, Kolar and Mysore. In the state, area under maize cultivation is increasing at a rapid pace because of the favourable environment, higher yield and easy cultivable practices of crop (Archana, 2017).

The cultivation of maize is frequently challenged by diseases that results in both quantitative and qualitative loss in grain yield in spite of its highest genetic yield potential. Post-flowering stalk rots caused by Fusarium verticillioides is most destructive which decreases quantity as well quality of the grain and results in rise in cost of cultivation. In India, Mount Abu, Rajasthan was the place at which the Fusarium stalk rot disease was first reported (Arya and Jain, 1964). This disease is widely distributed in rainfed maize growing areas like Rajasthan, Uttar Pradesh, Delhi, Bihar, Jammu and Kashmir, Punjab, Haryana, Karnataka, Madhya Pradesh, West Bengal, Andhra Pradesh and Tamil Nadu where severe moisture stress arises after flowering period of the maize crop (Singh et al., 2012). The disease is mostly prevalent in areas with hot and dry climatic conditions particularly before or during pollination (Pascale et al., 2002; Doohan et al., 2003).

The disease was found to cause a decrease of 18.7 per cent cob weight and 11.2 per cent in grain weight in the diseased plants (Cook, 1978). Fusarium stalk rot is reported to cause 10-42 per cent yield loss in Karnataka (Harlapur et al., 2002), whereas All India Co- ordinated Research Project (Anon., 2014) on maize has estimated 38 per cent loss in total yield due to the disease. In Karnataka, hitherto, there were very few studies carried in identification of the resistance source to the Fusarium stalk rot disease as host plant resistance is considered as most eco-friendly, cost-effective and sustainable efficient strategy to manage the disease. Therefore a study was carried to screen maize inbred lines for resistance to Fusarium stalk rot disease.

\section{Materials and Methods}

A total of 50 inbred maize lines received from CIMMYT-Hyderabad, were screened against Fusarium stalk rot of maize under field conditions by artificial inoculation using syringe method during kharif 2017 at College of Agriculture, Mandya. Plants were raised in single row replicated plot of $2 \mathrm{~m}$ row length along with one susceptible check 30-B07 and one resistant check CM 202 with a spacing of $60 \mathrm{x} 20 \mathrm{~cm}$ and replicated twice. Recommended agronomic practices were followed to establish good crop stand (Plate $1)$.

\section{Artificial inoculation by syringe method}

The pathogen $F$. verticillioides was isolated by standard tissue isolation technique and mass multiplied by broth culturing on $0.2 \%$ YESB (Yeast Extract Sucrose Broth). The inoculum suspension containing $2 \times 10^{6}$ conidia/ml of $F$. verticillioides was injected diagonally using a syringe after pricking and making a hole of $2.0 \mathrm{~cm}$ with the help of the jabber in the second internode of 45-50 days old maize plants above the soil level (Plate 2) and after 25-35 days of inoculation, each inoculated stalk was observed for the Fusarium stalk rot symptom and disease scoring was done following 1-9 disease rating scale [Plate 3] (Anita, 2016). 


\section{Disease scoring}

Disease severity was recorded based on percentage discoloration of the maize stem by destructive sampling (stem splitting) method and scoring by 1-9 scale (Anita, 2016). The genotypes were grouped as Highly resistant (1-2), Resistant (2-3), Moderately resistant (34), Moderately susceptible (4-5), Susceptible (5-6) and highly susceptible (6-9).

\section{Results and Discussion}

Screening of the maize inbred lines against Fusarium stalk rot pathogen ( $F$. verticillioides)

Identification of novel sources of resistance to Fusarium stalk rot is important for developing disease-free hybrids which reduce the inoculum load, prolong the life of hybrids and reduce the cost of cultivation.

A total of 50 inbred maize lines received from CIMMYT-Hyderabad, were screened against Fusarium stalk rot of maize under field conditions by artificial inoculation using syringe method during kharif 2017 and the results are presented in table 1. Later, disease scoring was done following 1-9 disease rating scale and maize inbred lines were categorized into Highly Resistant, Resistant, Moderately Resistant, Moderately Susceptible, Susceptible and Highly Susceptible based on the disease reaction.

Out of fifty maize inbred lines screened against Fusarium stalk rot, none of the inbreds showed highly resistant reaction. Fourteen inbred lines VL1010764, VL05616, VL0511321， VL107730， VL1018807, VL1043, VL108808, VL1244, VL124, SNL153296, VL0512423, VL1047, VL1050, VL1053 expressed a resistant reaction with a mean disease score of 2.49 (Table 2). Afolabi et al., (2008) also identified four new resistant or highly resistant inbred lines viz., 02C14609, 02C14654, 02C14678 and 02C14643 to Fusarium stalk rot. Similar findings were reported by Bohra et al., (2001) wherein he obtained 10 germplasm of maize showing resistant reaction to Fusarium moniliforme. Qureshi et al., (2015) also reported four resistant lines to Fusarium stalk rot viz., Y5, Y9, Y12 and Y13 in both autumn and spring.

Fifteen inbred lines expressed moderately resistant reaction with a mean disease score of 3.43. Archana (2017) also reported two moderately susceptible lines viz., CM 202 and MAI 766 to Fusarium stalk rot. Similar results were found by Khokhar (2014), who identified twenty-nine moderately resistant lines to $F$. verticillioides by toothpick method.

Fourteen inbred lines expressed moderately susceptible reaction with a mean disease score of 4.73 while, four maize inbred lines recorded susceptible reaction with a mean disease score of 5.35 and three maize inbred lines showed highly susceptible reaction with a mean disease score of 6.65. These results are in confirmation with Qureshi et al., (2015) wherein forty-eight maize germplasms lines showed moderately susceptible reaction to highly susceptible reaction to Fusarium stalk rot. Similarly, Archana (2017) identified twenty moderately susceptible, fifty-three susceptible and thirty-eight highly susceptible genotypes to Fusarium stalk rot.

The susceptible check hybrid Hema (NAH 1137) recorded a susceptible reaction (5.2) wherein resistant check CM 202 recorded a moderately resistant reaction (3.5).

The results are in confirmation with Archana (2017) who also reported the susceptible reactions of hybrids Hema and Nithyashree shown with mean disease score of 6.1 and 5.5 in comparison to the resistant parent CM 202. 
Table.1 Screening of maize inbred lines against Fusarium stalk rot

\begin{tabular}{|c|c|c|c|c|c|c|c|c|c|c|c|}
\hline $\begin{array}{c}\text { SI. } \\
\text { No. }\end{array}$ & Inbreds & DS & DR & $\begin{array}{c}\text { Sl. } \\
\text { No. }\end{array}$ & Inbreds & DS & DR & $\begin{array}{c}\text { Sl. } \\
\text { No. }\end{array}$ & Inbreds & DS & DR \\
\hline $\mathbf{1}$ & VL109452 & 3.08 & MR & 20 & VL1043 & 2.42 & R & 39 & VL08880 & 3.21 & MR \\
\hline $\mathbf{2}$ & VL109480 & 3.31 & MR & 21 & VL108808 & 2.73 & R & 40 & SNL153223 & 6.45 & HS \\
\hline $\mathbf{3}$ & VL109287 & 4.60 & MS & 22 & VL1047 & 2.37 & R & 41 & VL058454 & 6.95 & HS \\
\hline $\mathbf{4}$ & VL1010764 & 2.10 & R & 23 & VL1050 & 2.69 & R & 42 & VL1017256 & 5.10 & S \\
\hline $\mathbf{5}$ & VL123 & 3.48 & MR & 24 & VL1018393 & 4.35 & MS & 43 & VL1016173 & 5.25 & S \\
\hline $\mathbf{6}$ & VL107730 & 2.46 & R & 25 & VL1053 & 2.15 & R & 44 & VL1242 & 4.60 & MS \\
\hline $\mathbf{7}$ & VL1217 & 4.70 & MS & 26 & VL0512388 & 3.61 & MR & 45 & VL1244 & 2.69 & R \\
\hline $\mathbf{8}$ & VL1219 & 4.18 & MS & 27 & VL1018419 & 4.65 & MS & 46 & VL1249 & 2.53 & R \\
\hline $\mathbf{9}$ & VL109293 & 4.02 & MS & 28 & SNL153296 & 2.13 & R & 47 & VL057982 & 3.49 & MR \\
\hline $\mathbf{1 0}$ & VL1223 & 3.33 & MR & 29 & VL0512423 & 2.62 & R & 48 & VL1033 & 3.58 & MR \\
\hline $\mathbf{1 1}$ & VL05616 & 2.68 & R & 30 & SNL142663 & 4.48 & MS & 49 & VL1012849 & 3.50 & MR \\
\hline $\mathbf{1 2}$ & VL073318 & 3.33 & MR & 31 & VL1018640 & 4.22 & MS & 50 & VL058727 & 3.65 & MR \\
\hline $\mathbf{1 3}$ & VL0511321 & 2.78 & R & 32 & VL1055 & 6.57 & HS & & NAH 1137 & 5.2 & S \\
\hline $\mathbf{1 4}$ & VL108496 & 3.25 & MR & 33 & VL105611 & 4.40 & MS & & CM202 & 3.5 & MR \\
\hline $\mathbf{1 5}$ & VL108750 & 4.38 & MS & 34 & VL105612 & 4.00 & MS & & F & $*$ & $*$ \\
\hline $\mathbf{1 6}$ & VL1030 & 5.55 & S & 35 & VL1012756 & 3.67 & MR & & S. Em \pm & $\mathbf{0 . 1 9}$ \\
\hline $\mathbf{1 7}$ & VL1031 & 3.65 & MR & 36 & VL108849 & 4.59 & MS & CD $@ \mathbf{5 \%}$ & $\mathbf{0 . 5 4}$ \\
\hline $\mathbf{1 8}$ & VL1036 & 5.50 & S & 37 & VL1018803 & 4.40 & MS & & & & \\
\hline $\mathbf{1 9}$ & VL1018807 & 2.54 & R & 38 & VL108867 & 3.45 & MR & & & \\
\hline
\end{tabular}

*Significant at 5\% level; DS: Disease Score, DR: Disease reaction, HR: Highly resistant, R: Resistant, MR: Moderately Resistant, MS: Moderately susceptible, S: Susceptible, HS: Highly susceptible

Table.2 Classification of maize inbred lines screened against Fusarium stalk rot into different disease reaction classes

\begin{tabular}{|c|l|l|c|}
\hline $\begin{array}{c}\text { Sl. } \\
\text { No. }\end{array}$ & $\begin{array}{c}\text { Disease } \\
\text { reaction }\end{array}$ & \multicolumn{1}{|c|}{ Inbred lines } & $\begin{array}{c}\text { Disease reaction } \\
\text { range }\end{array}$ \\
\hline $\mathbf{1}$ & $\begin{array}{l}\text { Highly } \\
\text { resistant }\end{array}$ & \multicolumn{1}{|c|}{0} & - \\
\hline $\mathbf{2}$ & Resistant & $\begin{array}{l}\text { VL1010764, VL05616, VL0511321, VL107730, } \\
\text { VL1018807, VL1043, VL108808, VL1244, } \\
\text { VL1249, SNL153296, VL0512423, VL1047, }\end{array}$ & $2.10-2.78$ \\
\hline $\mathbf{3}$ & $\begin{array}{l}\text { VL1050, VL1053 } \\
\text { Mesistant }\end{array}$ & $\begin{array}{l}\text { VL109452, VL109480, VL123, VL1223, } \\
\text { VL073318, VL108496, VL1031, VL0512388, }\end{array}$ & \\
\hline & $\begin{array}{l}\text { VL1012756, VL108867, VL08880, VL057982, } \\
\text { VL1033, VL1012849, VL058727 }\end{array}$ & $3.08-3.67$ \\
\hline $\mathbf{4}$ & $\begin{array}{l}\text { Moderately } \\
\text { susceptible }\end{array}$ & $\begin{array}{l}\text { VL109287, VL1217, VL1219, VL109293, } \\
\text { VL108750, VL1018393, VL1018419, SNL142663, }\end{array}$ & \\
\hline & $\begin{array}{l}\text { VL1018640, VL105611, VL105612, VL108849, } \\
\text { VL1018803, VL1242 }\end{array}$ & $4.00-4.70$ \\
\hline $\mathbf{5}$ & Susceptible & VL1030, VL1036, VL1017256, VL1016173 & $5.10-5.55$ \\
\hline $\mathbf{6}$ & $\begin{array}{l}\text { Highly } \\
\text { susceptible }\end{array}$ & VL1055, SNL153223, VL058454 & $6.45-6.95$ \\
\hline
\end{tabular}




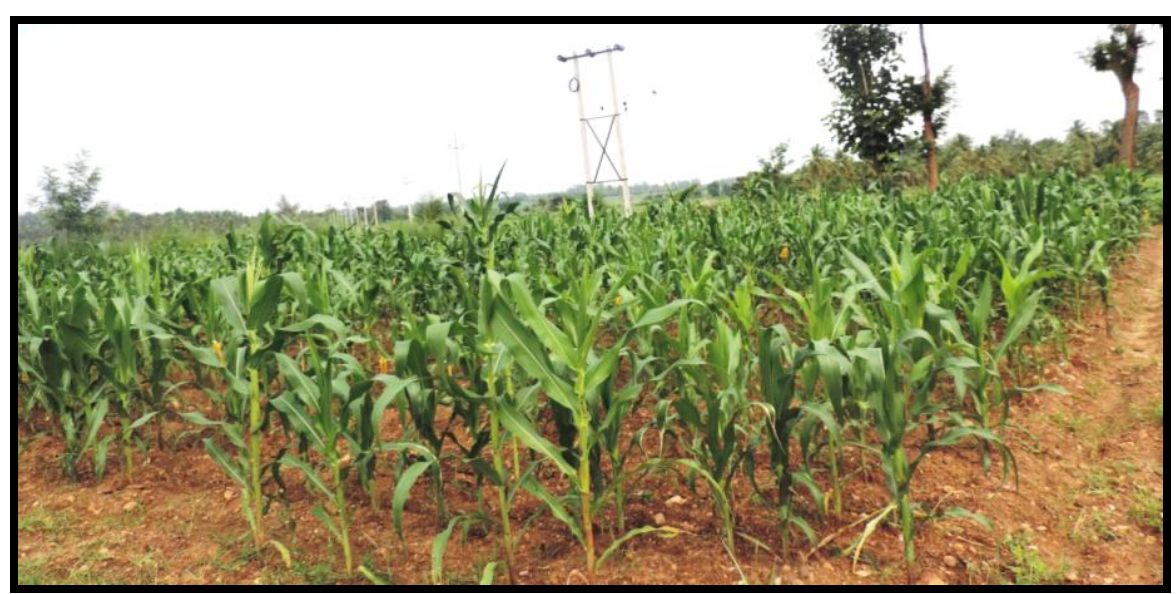

Plate.1 Screening of maize inbred lines against Fusarium stalk rot (F. verticillioides) under field conditions

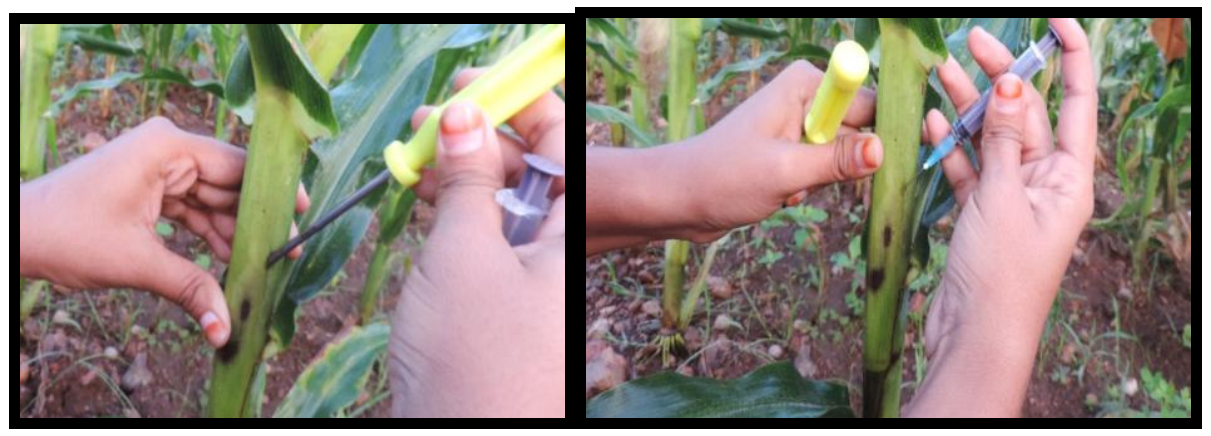

Plate.2 Injection of spore suspension into the stalk by syringe

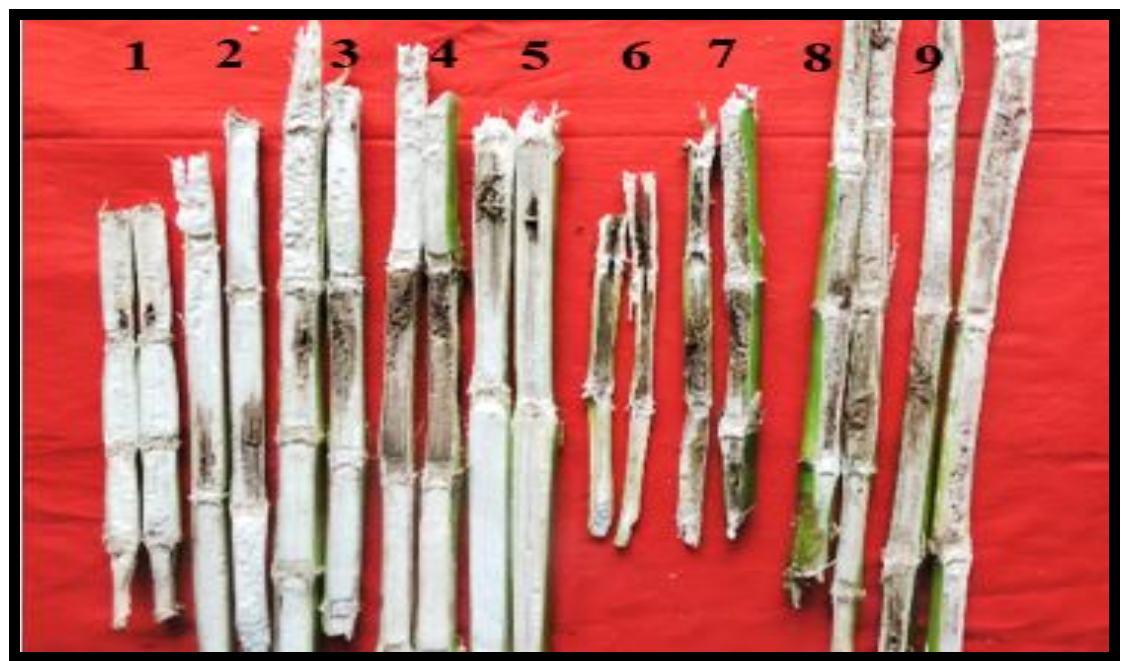

Plate.3 Disease rating scale of Fusarium stalk rot of maize (F. verticillioides)

Since, the Fusarium stalk rot appears during post flowering stage and causing high yield loss, use of resistant varieties is the best management strategy which is feasible and economical to reduce the yield loss. Hence, the inbreds screened for Kharif season and found resistant against Fusarium stalk rot, could be used as breeding material for the development of resistant maize cultivar. 


\section{References}

Afolabi, C. G., Ojiambo, P. S., Ekpo, E. J. A., Menkir, A. and Bandyopadhyay, R.. 2008. Novel sources of resistance to Fusarium stalk rot of maize in tropical Africa. Pl. Dis. 92(5): 772-780.

Anita, J. 2016. Source of Resistance and Management of Post Flowering Stalk Rot (PFSR) of Specialty Corn Caused by Fusarium verticillioides Sheldon. M.

Sc Thesis, Maharana Pratap Univ. Agric. Tech., Udaipur

Anonymous. 2012. Maize-Origin, Geographical distribution, Economic importance, Soil and Climatic requirement, Varieties, Cultural practices and Yield.

Anonymous. 2014. Annual Report of AICRP on Maize Pathology, Udaipur centre.

Anonymous. 2017. Director's review: annual maize workshop MPUAT, Udaipur.

Archana, R.. 2017. Genetics of resistance to Fusarium stalk rot in maize (Zea mays L.). M. Sc. (Agri.) Thesis, Univ. Agric. Sci., Bengaluru, Karnataka.

Arya, H. C. and Jain, B. L. 1964. Fusarium seedling blight of maize in Rajasthan. Indian Phytopath. 17: 51-57.

Bohra, B., Rathore, R. S. and Jain, M. L. 2001. Management of Fusarium stalk rot of maize caused by Fusarium moniliforme Sheldon. J. Mycol. Pl. Pathol. 31(2): 245-246.

Cook, R. J. 1978. The incidence of stalk rot (Fusarium spp.) on maize hybrids and its effect on yield of maize in Britain. Ann. Appl. Biol. 88: 23-30.
Doohan, F. M., Brennan, J. and Cooke, B. M. 2003. Influence of climatic factors on Fusarium species pathogenic to cereals. Eur. J. Plant Pathol.109: 755-768.

Harlapur, S. I., Wali M. C., Prashan, M. and Shakuntala, N. M. 2002. Assessment of yield losses in maize due to charcoal rots in Ghataprabha Left Bank Canal (GLBC) Command area of Karnataka. Karnataka J. Agric. Sci. 15: 590-91.

Khokhar, M. K. 2014. Epidemiology and management of post flowering stalk rot (PFSR) of maize caused by Fusarium verticillioides(Sacc). Ph.D. Thesis, MPUAT, Udaipur, Rajasthan., 173pp.

Pascale, M., Visconti, A. and Chelkowsky, J. 2002. Ear rot susceptibility and mycotoxin contamination of maize hybrids with Fusarium species under field conditions. Eur. J. Plant Pathol. 108: 645-651.

Qureshi, S. H., Qayyum, A. and Fiers, W. 2015. Sources of genetic resistance in maize to Fusarium stalk rot and their variations at molecular level. Turk. $J$. Agric. For. 39: 503-513.

Sandhu, K. S., Singh, N. and Malhi, N. S. 2007. Some properties of corn grains and their flours I: Physicochemical, functional and chapati-making properties of flours. Food Chemistry. 100(3): 938-946.

Singh, N., Rajendran, A., Meena, S. and Mittal, G. 2012. Biochemical response and host-pathogen relation of stalk rot fungi in early stages of maize (Zea mays L). African J. Biotech. 11(82): 1483714843

\section{How to cite this article:}

Ayesha Tabassum, V. B. Sanath Kumar and Kiran Kumar, N. 2020. Screening of Maize Germplasm for Resistance against Fusarium Stalk Rot caused by Fusarium verticillioides. Int.J.Curr.Microbiol.App.Sci. 9(05): 3155-3160. doi: https://doi.org/10.20546/ijcmas.2020.905.374 